\title{
Abrasive tool for processing components made from chrome-nickel steels and alloys
}

\author{
Victor Butenko ${ }^{1}$, Valery Lebedev ${ }^{1}$, Irina Davydova ${ }^{1, *}$, and Georgy Serga ${ }^{2}$ \\ ${ }^{1}$ Don State Technical University, 1, Gagarin sq., Rostov-on-Don, 344000, Russia \\ ${ }^{2}$ Kuban State Agrarian University, 13, Kalinin St., Krasnodar, 350044, Russia
}

\begin{abstract}
Abstarct. The technology of obtaining an abrasive tool on a ceramic bond for surfacing components made of chrome-nickel steels and alloys including the composition of the abrasive mass with wood flour, and the process of tool impregnation with an aqueous solution of chrome diiodide are considered. The comparison results on the efficiency of grindstones made according to the developed technology with their redress life between two consecutive shapings, and the performance quality indices of the processed component surfaces are presented. An empirical dependence of the efficient grindstone life between two consecutive shapings on the component speed, length feed, infeed movement, and the chrome diiodide saturation in the impregnated grindstone, is obtained. It can be used by production managers to optimize the modes of surfacing components from chrome-nickel steels and alloys providing the required performance quality indices. The mechanism of loss of function of the grindstone impregnated with chrome diiodide is considered.
\end{abstract}

\section{Introduction}

Abrasive treatment of the components made of chrome-nickel steels and alloys is caused by a number of difficulties associated with high temperature in the tool - component surface contact area. Consequently, high process residual tensile stresses arise in the material of the component surface layer, and a large number of burns appears on the surface, which significantly reduces the performance properties of the component. The available ways to improve the performance indicators of abrasive tools for machining components from chrome-nickel steels and alloys associated, for example, with designing special grindstones [1-5] or with the activation of the used cutting/cooling process media [6-10], are often expensive and do not always provide the required quality of the component surface layer, as they are most often meant for processing low-alloy steels. Thuswise, a wide use of the components made of hard-to-treat chrome-nickel steels and alloys in the modern aircraft engine-building, generates a need for manufacturing cheap and efficient abrasive tools.

\footnotetext{
*Corresponding author: davira2016@mail.ru
} 


\section{Materials and Methods}

To solve the problem of an extensive use of cheap and highly efficient abrasive tools for finishing components made of chrome-nickel steels and alloys in the modern metalworking, the known technology of making grindstones on a ceramic bond is applied. It takes into account the positive effect of the abrasive tool impregnation with chrome diiodide [10].

The abrasive mass for making a tool (for example, a grindstone) contains the following components: abrasive material of a specified grit, tempered clay to create a bond between the abrasive grains of the tool, and wood flour with the particle size approximately equal to the average size of the abrasive grains. The latter is introduced into the abrasive mass to create additional pores inside the tool, resulting from the combustion of wood flour particles in the firing process, as well as to produce wood ash meant for the subsequent stabilization of iron iodides formed on the treated surface.

The studies show that the tailored composition of the abrasive mass for the toolmaking is obtained with the following component ratios (wt.,\%): abrasive - $60-80$; wood flour -4 - 5; clay - the rest.

The abrasive mass prepared after thorough mixing in paddle mixers is formed in a molding unit under the pressure of at least $30 \mathrm{MPa}$, dried, fired at the temperature of 1100 $1250^{\circ} \mathrm{C}$, and then is slowly cooled indoors.

The obtained abrasive tool is subjected to impregnation with an aqueous solution of chrome diiodide using the technology that includes the following operations:

- preparation of the aqueous solution containing 20-25 g of chrome diiodide per liter of water in a special container (for example, a tank);

- heating of the aqueous solution of chrome diiodide to boiling;

- dipping of the abrasive tool into a boiling aqueous solution of chrome diiodide;

- soaking of the abrasive tool in a boiling aqueous solution of chrome diiodide for the time determined by $T_{n}=3.2 \times 10^{-3} v^{1.15} \mathrm{~min}$. formula, where $v$ is volume of the abrasive tool in $\mathrm{cm}^{3}$;

- removing of the abrasive tool from the tank with the boiling aqueous solution of chrome diiodide;

- convection drying of the abrasive tool through blowing it by a fan that supplies air heated to the temperature of $40-50^{\circ} \mathrm{C}$ for 1.5 to 2 hours while rotating the tool with the angular velocity of $0.3-0.5 \mathrm{~s}^{-1}$;

- explicit inspection of the impregnated abrasive tool.

The chrome-diiodide film formed under impregnation on the working surfaces of the abrasive grains and inside the ceramic bond pores, degrades at the grinding temperature to release free iodine, which creates iron iodides that have a layered structure and act as a solid lubricant on the treated surface [11]. Upon reducing the friction coefficient between the ceramic bond and the surface layer of the part material, the temperature in the contact area of the abrasive tool grains and the processed surface decreases, and the performance indicators of the component improve.

Abrasive sticks to finish the machinery part surfaces or to perform superfinishing can be made through the same technology. In this case, the convection drying of the impregnated abrasive sticks with a fan is recommended to be carried out on special rotating racks for 11.5 hours with their continuous flipping.

Metallographic studies of the working surface of abrasive tools allow us to suggest the following mechanism for the loss of function of the abrasive tools impregnated with chrome diiodide. If under processing components from chrome-nickel steels and alloys, the loss of the standard grindstone workability is due to the smearing [12], then the loss of function of the proposed grindstones impregnated with chrome diiodide is caused mainly by the abrasive grain breakdown. 


\section{Results}

A comparative analysis of the efficiency of grindstones of $\mathrm{D} \times \mathrm{H} \times \mathrm{d}=400 \times 60 \times 127 \mathrm{~mm}$ size, made from the proposed abrasive mass according to the developed technology, and of the PP $400 \times 60 \times 127$ 14A F60 K7V 35 m/s GOST R 52781-2007 standard wheels under processing cylindrical rollers with $24 \mathrm{~mm}$ in diameter and $320 \mathrm{~mm}$ long from 12X2H4A, $\mathrm{X} 18 \mathrm{H} 9 \mathrm{~T}$ steels and XH62MVKYu, HN77TYuR alloys are carried out. 14A regular alumina of F60 grit was also used to manufacture grindstones. The components were treated on the OD machine of 3M151 model using a five-percent aqueous solution of "Ukrinol-1" emulsol as a lubricant coolant. Grinding modes for each grade of steel or alloy were set according to the guidelines given in [12-13]. The grindstones efficiency was evaluated by their redress life between two successive resharpenings (tח) and the quality indices of the machined part surfaces: surface roughness $(\mathrm{Ra})$, process residual stress rates $(\sigma \circ \mathrm{\sigma oc})$, thickness of the layer with the modified physicomechanical properties $(\Delta \mathrm{H})$, and relative burn areas $(\Delta \mathrm{S})$.

To determine the quality indices of the machined part surfaces, the devices and apparatus described in [13] were used.

The results of the grindstone utilization efficiency are given in Table 1. Its analysis shows that the proposed abrasive tool enables to reduce the roughness parameter of the treated surface $(\mathrm{Ra})$ by $1.2-1.3$ times, to decrease the process residual stresses $($ бост) by $25-30 \%$, to reduce the thickness of the surface layers with the altered physicomechanical properties $(\Delta \mathrm{H})$ by $30-50 \%$, and to cut the surface area subjected to burns by more than twofold. At the same time, the efficient life of the proposed grindstone between two successive dressings (tп) has increased by $2.1-2.5$ times.

Table 1. Results of the grindstone utilization efficiency.

\begin{tabular}{|c|c|c|c|c|c|c|}
\hline \multirow{2}{*}{$\begin{array}{c}\text { Process } \\
\text { material }\end{array}$} & Used & \multirow{2}{*}{$\begin{array}{c}t_{n} \text { efficient } \\
\text { life, min }\end{array}$} & \multicolumn{4}{|c|}{ Quality indices of surface layer } \\
\cline { 4 - 7 } & & & $R a, \mathrm{~m}$ & $\sigma_{\text {ocm }}, \mathrm{MPa}$ & $\begin{array}{c}\Delta H, \\
\mathrm{~mm}\end{array}$ & $\Delta S, \%$ \\
\hline $\begin{array}{c}12 \mathrm{X} 2 \mathrm{H} 4 \mathrm{~A} \\
\text { steel }\end{array}$ & standard & 120 & 2.49 & 360 & 0.40 & 18 \\
\cline { 4 - 7 } & proposed & 250 & 1.75 & 240 & 0.24 & 9 \\
\hline X18H9T steel & standard & 110 & 2.68 & 350 & 0.42 & 20 \\
\cline { 2 - 7 } & proposed & 230 & 1.86 & 260 & 0.27 & 10 \\
\hline $\begin{array}{c}\text { XH62MVKYu } \\
\text { alloy }\end{array}$ & standard & 80 & 3.07 & 380 & 0.46 & 25 \\
\cline { 2 - 7 } & proposed & 190 & 2.15 & 270 & 0.26 & 11 \\
\hline $\begin{array}{c}\text { HN77TYuR } \\
\text { alloy }\end{array}$ & standard & 70 & 3.23 & 380 & 0.47 & 26 \\
\cline { 2 - 7 } & proposed & 180 & 2.19 & 300 & 0.27 & 12 \\
\hline
\end{tabular}

High efficiency of the proposed grindstones for surfacing components made of chromenickel steels and alloys is also validated by the narrowing of the scattered fields of the quality indices of the surface layer, which significantly improves the performance properties of the components. Table 2 shows the values of the scattered fields of roughness parameters $(\Delta \mathrm{Ra})$, process residual stresses $(\Delta \sigma \mathrm{oc})$, and thickness of the surface layer with the modified physicomechanical properties $(\Delta \Delta \mathrm{H})$ obtained as the difference between their maximum and minimum values in the part lots using standard and proposed grindstones.

The wear process of the friction pairs, which included components made from $\mathrm{XH} 62 \mathrm{MVKYu}$ alloy treated by the standard and proposed grindstones of 14A regular alumina of F60 grit under the same modes and cutting conditions, was studied on the material tester under extreme conditions [13]. 
Table 2. Scattered fields of quality indices of surface layer of components $\left(\Delta R a, \Delta \sigma_{o c m}, \Delta \Delta H\right)$ through using standard and proposed grindstones.

\begin{tabular}{|c|l|c|c|c|}
\hline Process material & \multicolumn{1}{|c|}{ Used grindstone } & $\Delta R a, \mathrm{~m}$ & $\begin{array}{c}\Delta \sigma_{\text {ocm }}, \\
\mathrm{MPa}\end{array}$ & $\begin{array}{c}\Delta \Delta H, \\
\mathrm{~mm}\end{array}$ \\
\hline \multirow{2}{*}{ 12XH3A steel } & standard & 0.42 & 60 & 0.12 \\
\cline { 2 - 5 } & proposed & 0.27 & 40 & 0.08 \\
\hline \multirow{2}{*}{ X18H9T steel } & standard & 0.48 & 70 & 0.12 \\
\cline { 2 - 5 } & proposed & 0.28 & 40 & 0.08 \\
\hline \multirow{2}{*}{ XH62MVKYu alloy } & standard & 0.54 & 90 & 0.14 \\
\cline { 2 - 5 } & proposed & 0.32 & 50 & 0.10 \\
\hline \multirow{2}{*}{ HN77TYuR alloy } & standard & 0.55 & 90 & 0.15 \\
\cline { 2 - 5 } & proposed & 0.34 & 50 & 0.12 \\
\hline
\end{tabular}

The studies were carried out without using solid lubricants under pressures of the contacting surfaces of the workpieces $(\mathrm{p}=5 \mathrm{MPa})$, sliding speed $($ Vск $=1.5 \mathrm{~m} / \mathrm{s}$ ), temperature $\left(\Theta=300^{\circ} \mathrm{C}\right)$ in the chamber with abrasive dust concentration of $5 \mathrm{~g} / \mathrm{dm} 3$. Under these conditions, the average wear rate of the components treated by standard wheels was $\mathrm{I}=10.8 \mathrm{mg} / \mathrm{min}$, and the average wear rate of components treated with the proposed grindstone was $\mathrm{I}=4.6 \mathrm{mg} / \mathrm{min}$.

Using the experimental design technique of 24 type, an empirical dependence of the redress life of the proposed grindstone between two successive reshapings (tп) on the component rotation speed (Vд) (when grinding the outside and inside cylindrical surfaces), length feed (Sвр), infeed movement (Sвр) and $\mathrm{Km}$ index characterizing the relative concentration of chrome diiodide in the impregnated $\mathrm{Km}$ grindstone was obtained:

$$
K_{m}=\frac{\left(m_{2}-m_{1}\right) 10^{3}}{m_{1}}, \mathrm{mg} / \mathrm{g}
$$

where $\mathrm{ml}$ is grindstone weight before impregnation, $\mathrm{g}$;

$\mathrm{m} 2$ is grindstone weight after impregnation, $\mathrm{g}$.

When grinding cylindrical and flat surfaces of machine parts, this relationship is as follows:

$$
t_{n}=C_{t} \cdot V_{s h}^{a} \cdot S_{L}^{b} \cdot S_{f}^{c} \cdot K_{m}^{d}
$$

where $\mathrm{Ct}$, a, b, c, d are coefficient and exponents taken from Table 3.

The dependence (2) is valid when using a five-percent aqueous solution of "Ukrinol-1" emulsol as a coolant under the following ranges of parametric variation of the surface grinding modes of the machine parts: grindstone speed is $\mathrm{V \kappa p}=20-50 \mathrm{~m} / \mathrm{s}$, component (of the work surface) rotation speed is $V_{\text {sh }}=0.2-0.8 \mathrm{~m} / \mathrm{s}$, length feed is $S_{\mathrm{L}}=10-30 \mathrm{~mm} / \mathrm{s}$, infeed movement is $\mathrm{S}_{\mathrm{f}}=0.05-0.20 \mathrm{~mm} /$ double stroke, relative concentration of chrome diiodide in the impregnated tool is $\mathrm{KT}_{\mathrm{T}}=5-15 \mathrm{mg} / \mathrm{g}$.

The studies show that the redress life of the proposed tn grindstone calculated by the formula (2) can be increased in 2 - 3 times when using cutting fluids subjected to activation in the magnetic field or to the ultrasonic vibration impact $[1,8-10]$.

Table 3. Values of $C_{t}$ coefficient and $a, b, c, d$ exponents in the formula for determining wheel life between two successive reshapings $\left(t_{n}\right)$.

\begin{tabular}{|c|c|c|c|c|c|c|}
\hline $\begin{array}{c}\text { Yield strength of the } \\
\text { work material, } \sigma_{m}, \mathrm{MPa}\end{array}$ & $\begin{array}{c}\text { Part working } \\
\text { surface }\end{array}$ & $C_{t}$ & $a$ & $b$ & $c$ & $d$ \\
\hline up to 300 & outside & 54.6 & 0.491 & 0.312 & 0.547 & 0.873 \\
\cline { 2 - 7 } & inside & 47.3 & 0.516 & 0.309 & 0.525 & 0.730 \\
\hline
\end{tabular}




\begin{tabular}{|c|c|c|c|c|c|c|}
\hline & flat & 61.4 & 0.462 & 0.387 & 0.578 & 0.895 \\
\hline from 301 to 350 & outside & 49.7 & 0.504 & 0.342 & 0.565 & 0.846 \\
\cline { 2 - 7 } & inside & 40.8 & 0.536 & 0.289 & 0.501 & 0.713 \\
\cline { 2 - 7 } & flat & 58.9 & 0.451 & 0.413 & 0.532 & 0.857 \\
\hline from 351 to 400 & outside & 45.6 & 0.528 & 0.364 & 0.549 & 0.815 \\
\cline { 2 - 6 } & inside & 37.5 & 0.574 & 0.273 & 0.486 & 0.692 \\
\cline { 2 - 6 } & flat & 53.1 & 0.433 & 0.452 & 0.556 & 0.828 \\
\hline over 400 & outside & 41.3 & 0.548 & 0.379 & 0.551 & 0.789 \\
\cline { 2 - 6 } & inside & 33.7 & 0.584 & 0.261 & 0.446 & 0.665 \\
\cline { 2 - 7 } & flat & 50.9 & 0.426 & 0.473 & 0.588 & 0.804 \\
\hline
\end{tabular}

It is found that the use of the proposed abrasive tool for processing chrome-nickel steels and alloys enables to obtain the required quality indicators of the component surface layer for fewer passes of the grindstone without subsequent sparking-out, which leads to a decrease in the allowance amount. However, the studies found that under grinding the component surfaces by the impregnated abrasive tools, chrome diiodide is gradually washed out by the used cutting fluid. To eliminate this phenomenon, it is advisable to add 5 - $10 \mathrm{~g} / \mathrm{l}$ of the finely ground chrome diiodide to the used coolant, which will ensure the continuous availability of chrome diiodide in the abrasive grain - workpiece surface contact area.

\section{Conclusion}

The studies show high efficiency of the abrasive tools made according to the developed technology and used for machining parts made from chrome-nickel steels and alloys. An apparent increase in the redress life between two consecutive reshapings of the proposed grindstones under the simultaneous improvement of quality indices of the machined part surfaces, and minor costs of making such abrasive tools are the basis for their wides use in the modern aircraft industry when finishing components made from chrome-nickel steels and alloys.

\section{References}

1. S.A. Kryukov, M.A. Tkach, Procedia Engineering 206, 200-203 (2017)

2. J. Zeisig, N. Schädlich, L. et.al, Microstructure and abrasive wear behavior of a novel FeCrMoVC laser cladding alloy for high-performance tool steels. Wear/RG Journal Impact Rankings $\wedge$. 382-383, 107-112 (2017)

3. L.V. Shipulin, A.A. Dyakonov, M.M. Al-Aqeeli, Procedia Engineering 206, 12111214 (2017)

4. H. Yamaguchi, J. Kang, F. Hashimoto, CIRP Annals 60(1), 339-342 (2011)

5. V.M. Shumyacher, P.U. Bochkarev, A.V. Slavin, Procedia Engineering 206, 232-235 (2017)

6. E. Averin, Engineering 3(6), 888-891 (2017)

7. V.G. Poltoratskiy, V.I. Lavrinenko, et.al, Diamond and Related Materials 68, 66-70 (2016)

8. V.K. Prokudina, Abrasives. Concise Encyclopedia of Self-Propagating HighTemperature Synthesis (2017)

9. V.I. Butenko (DSTU Publ. Center, Rostov-on-Don, 2016) 
10. H. Yamaguchi, A.K. Srivastava, M. Tan, F. Hashimoto, CIRP Journal of Manufacturing Science and Technology 7(4), 299-304 (2014)

11. L. Yang, D. Wang, Y. Guo, Tribology International 123, 180-190 (2018)

12. B. Gupta, A. Jain, R. Purohit, R.S. Rana, B. Gupta, Materials Today: Proceedings 5(9)3, 17725-17729 (2018) 